\title{
KAKO MLADIM DELAVCEM PRIBLIŽATI VARNOST IN ZDRAVJE PRI USPOSABLJANJU ZA DELO
}

\section{POVZETEK}

Podatki Evropske skupnosti kažejo, da je mlada delovno aktivna populacija v starosti od 18 do 24 let zlasti zaradi pomanjkanja izkušenj in znanja o zagotavljanju varnosti in zdravja pri delu ter nezadostne usposobljenosti za varno in zdravo delo posebej ogrožena $v$ smislu večjega tveganja poškodb pri delu in poklicnih bolezni $v$ primerjavi s preostalo delovno populacijo. Delodajalci morajo vzpostaviti ustrezen sistem za zagotavljanje varnosti in zdravja pri delu s poudarkom na usposabljanju za varno delo dijakov in študentov, ki so na delovni praksi, ter novozaposlenih mladih oseb. Ministrstvo za delo, družino, socialne zadeve in enake možnosti vodi vrsto projektov promocije varnosti in zdravja pri delu, s katerimi si prizadeva spodbuditi kulturo varnosti med mladimi $v$ Sloveniji. Cilj nacionalnega programa uvajanja varnosti in zdravja pri delu v vzgojo in izobraževanje je, da vzgojiteljem in učiteljem ponudi različna orodja in pripomočke, s katerimi bodo lahko mladim na zanimiv način približali varnost in zdravje pri delu.

Ključne besede: mladi delavci, nezgode pri delu, usposabljanje, kultura varnosti

\section{HOW TO BRING ISSUES OF HEALTH AND SAFETY CLOSER TO YOUNG WORKERS DURING THEIR WORK TRAINING - ABSTRACT}

The data collected by the European Community indicates that the young, economically active population, aged from 18 to 24 years, is more likely to suffer from occupational injuries and occupational diseases in comparison with the rest of the working population, due to the lack of experience and knowledge about health and safety in the workplace, and insufficient training for safe and healthy work practices. Employers must establish an adequate system to ensure workplace health and safety, with an emphasis on providing safety training for pupils and students undergoing apprenticeship and the newly-employed young people. The Ministry of Labour, Family, Social Affairs and Equal Opportunities runs a series of projects aiming to promote health and safety culture among young people in Slovenia. The goal of the national programme for introducing occupational health and safety into the education process is offering a variety of tools and devices for educators and teachers, which can be employed to introduce the issues of occupational health and safety to young people in an exciting and engaging manner.

Keywords: young workers, occupational injuries, training, safety culture

Mag. Helena Mesarič, Zavod za varstvo pri delu Ljubljana, helena.mesaric@zvd.si 


\section{NEZGODE MED MLADIMI DELAVCI}

Po podatkih Eurostata (Portal za varnost in zdravje pri delu, 2016) je v EU pogostost nezgod pri delu med delavci (»Delavec ali delavka (v nadaljnjem besedilu: delavec) je oseba, ki pri delodajalcu opravlja delo na podlagi pogodbe o zaposlitvi. Kot delavec v smislu tega zakona se šteje tudi oseba, ki na kakršnikoli drugi pravni podlagi opravlja delo za delodajalca, ali oseba, ki pri delodajalcu opravlja delo zaradi usposabljanja.« (Zakon o varnosti in zdravju pri delu, 2011)), starimi od 18 do 24 let, za več kot 40 odstotkov večja kot v drugih starostnih skupinah. Razlike med dejavnostmi in poklici so precejšnje. Najbolj nevarno je prvo leto zaposlitve.

Slovenski delodajalci so v letu 2014 Inšpektoratu RS za delo prijavili 8.793 nezgod pri delu. V nekaj manj kot 10 odstotkov nezgod so bili vpleteni delavci, stari manj kot 25 let. Evropska agencija za varnost in zdravje pri delu (EU-OSHA, 2006) kot razloge za pogoste nezgode pri delu med mladimi navaja:

- slabo usposobljenost za varno opravljanje delovnih nalog;

- neizkušenost mladih, ki se ne zavedajo tveganj, ki so jim izpostavljeni;

- nepoznavanje dolžnosti delodajalca na področju zagotavljanja varnosti in zdravja pri delu;

- nepoznavanje pravic in dolžnosti delavca;

- nizka zavest o pomembnosti varnosti in zdravju pri delu;

- $\quad$ vrste del in delovne razmere, $v$ katerih delajo mladi;

- nezrelost mladih delavcev.

Primer iz osebne prakse, maj 2015:

Dijak si je na delovni praksi poškodoval oko, ker kljub opozorilom mojstra pri razdiranju krogličnega ležaja ni uporabil zaščitnih očal. Sam pri sebi je namreč presodil, da obstaja minimalna verjetnost, da mu ležajna kroglica izleti $v$ obraz. Tě̌ji poškodbi očesa sta botrovali napačna presoja in neizkušenost mladega dijaka.

Podatki kažejo, da so mladi ljudje bolj podvrženi poškodbam kot starejši delavci, saj praviloma na začetku dela niso dovolj usposobljeni in nimajo zadostnih izkušenj z delovnimi sredstvi (ročno orodje, stroji in podobno). Obenem pa se pri delu želijo izkazati in dokazati, vendar so prav zaradi svoje starosti (psihofizična nezrelost) in neizkušenosti lahko bolj ranljivi in izpostavljeni večjemu tveganju pri delu. Teže tudi odkrito spregovorijo o morebitnih težavah in dilemah pri delu, ker se bojijo, da nadrejeni zanje ne bodo imeli razumevanja.

\section{ZAHTEVE PREDPISOV ZA VARNOST IN ZDRAVIE PRI MLADIH DELAVCIH}

Širša definicija mladih delavcev po zakonodaji (Zakon o delovnih razmerjih, 2013) zajema vse osebe, ki so mlajše od 18 let in opravljajo delo na kakršnikoli pravni podlagi. 
Delavcu, ki še ni dopolnil 18 let starosti, se ne sme naložiti:

- delo, ki se opravlja pod zemljo ali pod vodo,

- delo, ki objektivno presega njegove telesne in psihološke sposobnosti,

- delo, ki vključuje škodljivo izpostavljanje dejavnikom, ki so strupeni, karcinogeni, ki povzročajo dedne genske poškodbe ali škodujejo nerojenemu otroku ali kako drugače kronično vplivajo na človekovo zdravje,

- delo, ki vključuje škodljivo izpostavljanje sevanju,

- delo, ki vključuje tveganje za nesreče, ki ga mlada oseba ne more prepoznati ali se mu izogniti zaradi svoje nezadostne pozornosti do varnosti ali zaradi pomanjkanja izkušenj ali usposobljenosti,

- delo, ki vključuje tveganje za zdravje zaradi izjemnega mraza, vročine, hrupa ali vibracij (Zakon o delovnih razmerjih, 2013).

Delavcu, ki še ni dopolnil 18 let starosti, se tudi ne sme naložiti delo, pri katerem je izpostavljen dejavnikom tveganja, ter dela, ki so podrobneje določena s podzakonskim aktom, to je Pravilnikom o varovanju zdravja pri delu otrok, mladostnikov in mladih oseb (2015), če iz ocene tveganja izhaja nevarnost za varnost, zdravje in razvoj delavca.

V podzakonskem aktu so določeni tudi pogoji, pod katerimi lahko delavec, ki še ni dopolnil 18 let, izjemoma opravlja dela, ki so prepovedana, in sicer v primerih izvajanja praktičnega izobraževanja v okviru izobraževalnih programov, če se delo opravlja pod nadzorom pristojnega delavca. Zakon določa tudi omejitve glede opravljanja nočnega dela mladih delavcev, delovni čas, odmor in počitek.

Kategorija mladih delavcev vključuje tudi:

- delo otrok, mlajših od 15 let, ki sodelujejo pri snemanju filmov, pripravi in izvajanju umetnostnih, scenskih in drugih del s področja kulturne, umetniške, športne in oglaševalske dejavnosti;

- lažje delo otrok, starejših od 13 let, med šolskimi počitnicami, in sicer v obsegu in pod pogojem, da dela, ki jih bodo opravljali, ne ogrožajo otrokove varnosti, zdravja, morale, izobraževanja in razvoja;

- delo vajencev, dijakov in študentov, ki so dopolnili 14 let in opravljajo delo v okviru izobraževalnih programov oziroma praktičnega izobraževanja;

- začasno in občasno delo dijakov in študentov;

- delavce, starejše od 15 let in mlajše od 18 let, ki so zaposleni po pogodbi o zaposlitvi.

Varnost in zdravje mladih delavcev pri delu opredeljujejo krovna Direktiva Sveta 94/33/ ES (1994) in druge, ki določajo minimalne zdravstvene in varnostne zahteve $\mathrm{v}$ zvezi z izpostavljenostjo delavcev poklicnemu tveganju. V pravni red RS je vsebinsko prenesena tudi Okvirna direktiva Sveta 89/391/EGS (1989), ki med drugim določa, da morajo biti pred nevarnostmi in škodljivostmi pri delu še posebej zavarovane občutljive in rizične skupine.

Pravilnik o varovanju zdravja pri delu otrok, mladostnikov in mladih oseb (2015) opredeljuje mlado osebo, otroka in mladostnika na naslednji način: 
- mlada oseba je vsaka oseba pod 18. letom starosti, ki je v delovnem razmerju na podlagi pogodbe o zaposlitvi;

- otrok je vsaka oseba pod 16. letom starosti ali oseba, ki je vključena v obvezno redno šolanje;

- mladostnik je vsaka oseba, ki je stara vsaj 16 let ter ne več kot 18 let in ni več vključena v obvezno redno šolanje.

Prav tako določa splošne dolžnosti delodajalca, ki mora na podlagi ocene tveganja sprejeti potrebne ukrepe za varnost in zdravje otrok, mladostnikov in mladih oseb. Posebna pozornost je namenjena: opremljanju in načrtovanju delovnega mesta, naravi, stopnji in trajanju izpostavljenosti fizikalnim, biološkim in kemičnim škodljivostim, psihološkim ter drugim obremenitvam, obliki, vrsti in uporabi delovne opreme, strojev, aparatov in naprav ter načinu, kako jih uporabljajo, načrtovanju delovnih procesov in operacij ter organizaciji dela, stopnji izobraževanja, usposabljanja in inštrukcij pri mladih osebah. Delodajalec mlade osebe ali mladostnike obvesti o možnih tveganjih ter o vseh ukrepih za zagotovitev varnosti in zdravja. O možnih tveganjih ter vseh ukrepih za otrokovo varnost in zdravje delodajalec obvesti otrokove zakonite zastopnike. Delodajalec zagotovi varovalne in preventivne ukrepe za zdravo in varno delo otrok in mladostnikov, ki je primerno njihovi starosti. Pri tem vključi pooblaščenega zdravnika, strokovne delavce in druge strokovne službe. Na delovnih mestih, kjer iz ocene tveganja izhaja tveganje za varnost, telesno ali duševno zdravje ali za razvoj mladih oseb, delodajalec zagotovi reden zdravstveni nadzor in predhodne ter obdobne zdravstvene preglede mladih oseb. Obdobni usmerjeni zdravstveni pregledi se opravijo $\mathrm{v}$ obdobju, ki je navedeno $\mathrm{v}$ oceni tveganja in ni daljše od enega leta (Pravilnik o varovanju zdravja otrok, mladostnikov in mladih oseb, 2015).

$\mathrm{S}$ stališča zakonodaje je za delo dijaka ali študenta v celoti odgovorna oseba, pri kateri se izvaja delo. Zakon o varnosti in zdravju pri delu določa, da je delodajalec dolžan izvajati vrsto ukrepov z namenom obvladovanja in odpravljanja nevarnosti pri delu. $\mathrm{S}$ tem namenom pisno oceni tveganja, ki so jim pri delu izpostavljeni delavci ali bi jim lahko bili izpostavljeni.

Evropski in nacionalni viri (Evropska agencija za varnost in zdravje pri delu, 2007) kažejo, da so mladi delavci mnogo bolj izpostavljeni naslednjim fizikalnim dejavnikom pri delu: hrupu, vibracijam, vročini in mrazu ter ravnanju z nevarnimi snovmi. Glasnemu hrupu so izpostavljeni zlasti mladi, ki delajo v gostinstvu in gradbeništvu. Mladi delavci so tudi posebno dovzetni za poškodbe zaradi akustičnega šoka, saj pomenijo velik delež delovne sile, ki dela v klicnih centrih.

Rezultati študije Evropske agencije za varnost in zdravje pri delu (2007), ki temelji na nacionalnih virih in virih EU, kažejo, da mladi delavci v primerjavi z delovno aktivnim prebivalstvom povprečne starosti pogosteje opravljajo fizično zahtevno delo (kot je delo v prisilni drži, premeščanje težkih bremen in ponavljajoče se delo). Mladi delavci so zato izpostavljeni znatno večjemu tveganju za razvoj kostno-mišičnih obolenj (vključno z bolečinami v križu). Raziskave (Evropska agencija za varnost in zdravje pri delu, 2007) 
nadalje kažejo, da so mladi delavci očitno slabše obveščeni o tveganjih, povezanih z delom, ki ga opravljajo. Ker v današnjem svetu tempo življenja in dela narašča, morajo mladi čedalje pogosteje opravljati delo v kratkih rokih in z veliko hitrostjo. In čeprav študije kažejo, da mladi delajo manj ur kot delovno aktivno prebivalstvo povprečne starosti, opravljajo več izmenskega dela in imajo bolj neredne delovnike. Mladi delavci tudi pogosteje poročajo o nezaželeni spolni pozornosti. Pri mladih ženskah, ki opravljajo priložnostna dela v gostinstvu in storitvenih dejavnostih, je nekajkrat večja verjetnost, da bodo žrtve spolnega nadlegovanja.

Kot je razvidno iz Slike 1, obsega postopek ocenjevanja tveganja za varnost in zdravje delavcev pri delu šest temeljnih korakov.
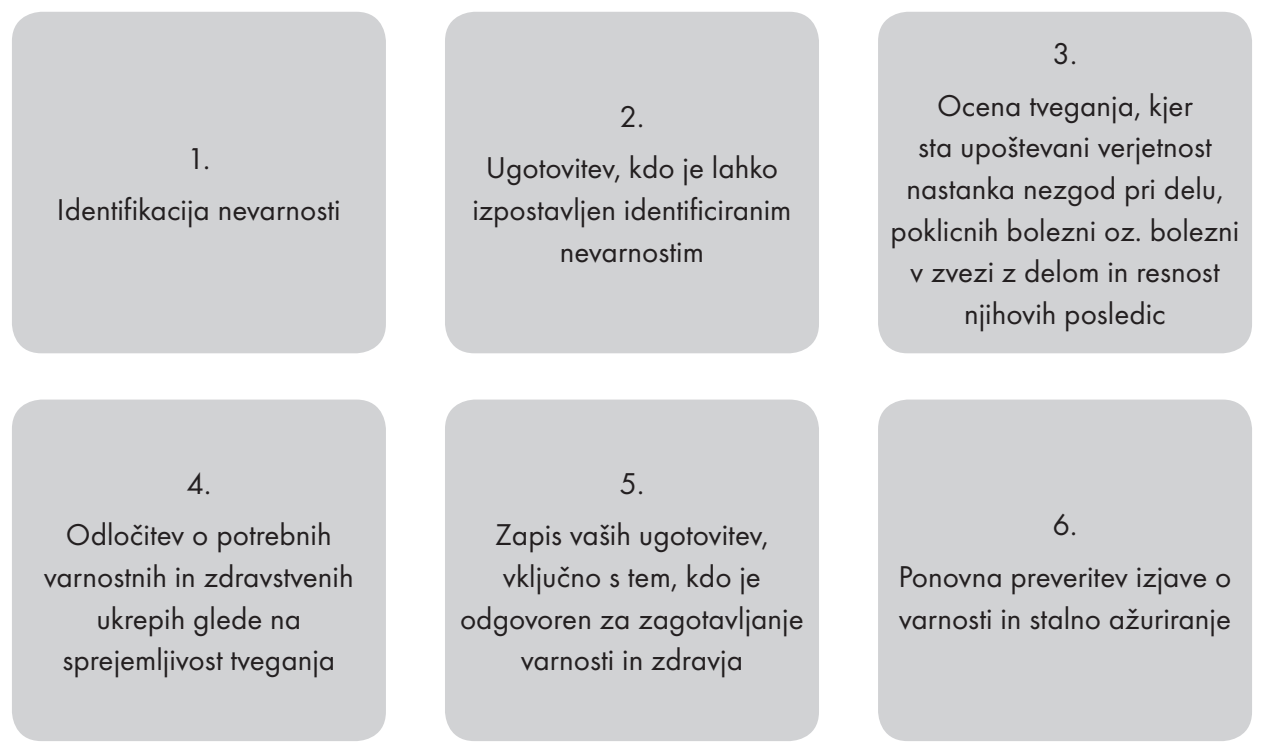

Slika 1: Postopek ocenjevanja tveganja za varnost in zdravje pri delu (Zakon o varnosti in zdravju pri delu, 2011)

Po izvedenem ocenjevanju tveganja mora delodajalec izdelati in sprejeti izjavo o varnosti $\mathrm{z}$ oceno tveganja. To je listina, $\mathrm{s}$ katero delodajalec pisno izjavi, da izvaja vse ukrepe za zagotovitev varnosti in zdravja pri delu, in sicer glede preprečevanja tveganja pri delu, obveščanja in usposabljanja delavcev, dajanja navodil, ustrezne organiziranosti ter zagotavljanja potrebnih materialnih sredstev v ta namen. Delodajalec mora izjavo o varnosti $\mathrm{z}$ oceno tveganja objaviti na običajen način in jo v delu, ki se nanaša nanje, posredovati delavcem vsakokrat, ko se spremeni in dopolni, prav tako pa tudi novozaposlenim in vsem drugim navzočim na delovnem mestu ob začetku dela (Zakon o varnosti in zdravju pri delu, 2011). 


\section{USPOSABLJANJE ZA VARNO IN ZDRAVO DELO}

Mladim delavcem je treba nameniti posebno pozornost pri izpolnjevanju vseh predpisanih obveznosti, med katerimi sta tudi zagotavljanje obveščanja delavcev s pisnimi navodili in obvestili z namenom seznanjanja z vrstami nevarnosti na delovnem mestu ter z varnostnimi ukrepi, potrebnimi za preprečevanje nevarnosti in zmanjšanje škodljivih posledic, in zagotavljanje usposabljanja delavcev za varno opravljanje dela.

Vzrok poškodb pri delu je pogosto pomanjkanje informacij in nekritično razmišljanje mladih, kar v nekaterih primerih spodbujajo sami delodajalci s tem, ko usposabljanja izvajajo v splošni obliki zgolj z namenom, da zadostijo zakonskim zahtevam.

Večina delodajalcev, kot ugotavljam iz svojih dolgoletnih strokovnih izkušenj, ne zaposluje svojega strokovnega delavca za področje varnosti pri delu, ampak se raje odločajo za sodelovanje z zunanjimi strokovnjaki, kar ima lahko nekatere prednosti, a tudi pomanjkljivosti, kot so:

- zunanji izvajalci pogosto ne poznajo zadosti vseh aktivnosti delodajalca, zato je nujno, da se program usposabljanja pripravi in izvede $\mathrm{v}$ sodelovanju $\mathrm{z}$ delodajalcem oziroma s strokovnimi in odgovornimi osebami, po potrebi pa tudi še z drugimi strokovnjaki, specialisti za posamezna področja;

- $\quad$ vsi izvajalci usposabljanj nimajo ustreznih andragoških znanj. Zgolj praktične izkušnje ne morejo nadomestiti tega, kar združuje in posplošuje andragoška teorija na podlagi izkušenj in znanstvenih raziskovanj ter izsledkov sorodnih ved.

Eden najpomembnejših preventivnih ukrepov delodajalca je usposabljanje delavcev za varno delo z namenom pridobivanja znanj, spretnosti in navad, ki delavcem omogočajo varno in zdravju neškodljivo opravljanje dela. $Z$ usposabljanjem želimo doseči takšne spremembe $\mathrm{v}$ stališčih in ravnanju posameznika, da bo ozaveščen in motiviran za varno delo. Izvajalec usposabljanja je običajno strokovna oseba delodajalca ali institucija oziroma zunanji strokovni delavec, ki ima ustrezno dovoljenje za izvajanje strokovnih nalog varnosti pri delu (dovoljenje za delo ministrstva za delo družino, socialne zadeve in enake možnosti, v nadaljevanju MDDSZ).

Zakon o varnosti in zdravju pri delu (2011) od delodajalca zahteva, da usposobi delavce pred nastopom dela, ob sklenitvi delovnega razmerja, pred razporeditvijo na drugo delo, pred uvajanjem nove tehnologije in novih sredstev za delo ter ob spremembi v delovnem procesu, ki lahko povzroči spremembo varnosti pri delu. Usposabljanje mora biti prilagojeno posebnostim delovnih mest, na katerih delajo delavci, ter se izvajati po vnaprej izdelanih programih, ki so vsebinsko prilagojeni vrstam tveganj za varnost in zdravje pri delu.

Skladno z načeli pedagoško-andragoške stroke se usposabljanje praviloma zaključi z ustreznim preizkusom pridobljenega znanja, veščin, načinov ravnanja in podobno. Tudi zakon sledi tem načelom, saj nalaga delodajalcem, da izvajajo občasne preizkuse teoretične in praktične usposobljenosti za varno delo za vse delavce, ki delajo na delovnih mestih, na katerih iz ocene tveganja izhaja, da na njih obstaja večja nevarnost za poškodbe ali 
zdravstvene okvare. Predpisan je tudi rok za izvedbo občasnih preizkusov, ki ne sme biti daljši od dveh let. Usposobljenost za varno delo preverja delodajalec na delovnem mestu.

Vse naštete zahteve $\mathrm{v}$ zvezi s pripravo in izvedbo usposabljanja pomenijo minimalni standard za vse zaposlene pri kateremkoli delodajalcu.

Kakovosten program teoretičnega in praktičnega usposabljanja temelji na analizi določenega opravila in funkcije, ki jo opravlja delavec. Izvajalec usposabljanja (na primer mentor pri praktičnem usposabljanju) mora vedeti, katera znanja in spretnosti naj udeleženec pridobi na usposabljanju. Preverjanje in ocenjevanje pridobljenega znanja in veščin je poseben izziv. Ne preverjamo samo znanje posameznika, temveč tudi njegove sposobnosti prenašanja naučenega v različne okoliščine ter oblikovanje kritičnega mišljenja.

Učinkovito usposabljanje delavcev oziroma mentorjev mladih mora:

- odsevati dejanske situacije, v katerih delavci opravljajo svoje naloge. V ta namen je treba predhodno pripraviti program, ki je skladen s posebnostmi delovnih mest, še pred tem pa proučiti vsa tveganja, ki nastopajo v delovnem procesu na posameznih delovnih mestih;

- biti prilagojeno sposobnostim posameznika za dojemanje novih spoznanj in informacij;

- izhajati predvsem iz tega, kar je delavcem psihološko in prostorsko bliže, iz njihovih delovnih in življenjskih izkušenj;

- biti sistematično in nazorno, kar bistveno olajša in pospešuje dojemanje in pomnjenje; - vsebovati aktivne metode dela, ki vodijo v kritično razmišljanje.

Sodobna andragoška načela zahtevajo ustrezne izobraževalce (strokovni delavec delodajalca, delovodja, mentor in podobno), primerne razmere (materialno-tehnična sredstva) in čas, ki je potreben za uresničevanje vzgojno-izobraževalnih nalog. Usposabljanje za varno delo na delovnem mestu je pomembna sestavina delovnega procesa, zato mora biti izvedeno in preverjeno tako v skladu z zahtevami dela kot z načeli vzgojno-izobraževalnega procesa. Slednje od izobraževalcev zahteva ustrezen andragoški pristop, kar je prvi pogoj za učinkovit vzgojno-izobraževalni proces, ki je usmerjen $\mathrm{k}$ doseganju pomembnega cilja, da mladim delavcem omogoči varen začetek poklicne poti.

\section{NADZOR MLADIH DELAVCEV PRI DELU IN ZGLED MENTORJEV}

Posebno problematično področje je pomanjkanje nadzora nad spoštovanjem varnostnih pravil. Preventivni varnostni postopki so sicer opredeljeni, vendar sistem pravil v praksi ne funkcionira.

Delodajalci morajo pripraviti oceno tveganja, ki identificira tveganja mladih delavcev pri delu. Na tej podlagi morajo biti vzpostavljeni mehanizmi preventivnih ukrepov za zmanjševanje tveganj, opredeljene obveznosti, pristojnosti in odgovornosti posameznika, vključno z režimom nadzora. 
Delavci oziroma mentorji, ki nadzirajo mlade, morajo dobro razumeti svojo vlogo. Vedeti morajo, kaj se od njih pričakuje in kako naj izvajajo nadzor, predvsem pa dajati dober zgled. Poudarjati, da je nevarno ravnanje nesprejemljivo, hkrati pa ne ravnati ustrezno pomeni slab zgled, ki ga mladi takoj opazijo.

Primer iz osebne prakse, avgust 2015:

Mojster je poučeval dijaka na delovni praksi o tehnikah varjenja, pri čemer sam ni uporabil zaščite za oči in obraz za zavarovanje pred neionizirajočim sevanjem.

Nadzor mladih delavcev obsega (povzeto po nasvetih Sveta za učenje spretnosti in Kraljeve družbe za preprečevanje nezgod, ROSPA, 2006):

- oceno sposobnosti/zmogljivosti za opravljanje nalog;

- $\quad$ ugotavljanje nevarnosti, zaradi katerih bi se lahko mladi poškodovali; mladi so bolj ranljivi in potrebujejo skrbnejši nadzor kot drugi delavci;

- vzpostavitev učinkovitih kontrolnih/varnostnih ukrepov za preprečevanje poškodb: osebna varovalna oprema, obveščanje, usposabljanje, postopki in nadzor;

- $\quad$ stalno izboljševanje in poenostavljanje varnih delovnih praks;

- obveřčanje in poučevanje o dobri praksi;

- $\quad$ izvajanje praktičnega prikaza pravilnega postopka; po potrebi naj se prikaz izvede počasi;

- dodelitev nalog v skladu s posameznikovimi sposobnostmi in zagotavljanje neposrednega nadzora, dokler ni sposoben samostojno opravljati nalog;

- preverjanje njegovega razumevanja pravilnega postopka in potrebnih varnostnih ukrepov;

- opazovanje njegovega dela in po potrebi ponovitev prikaza za izboljšanje razumevanja;

- $\quad$ poslušanje posameznikov, posvetovanje z njimi in izmenjava mnenj, na primer z njihovo vključitvijo v pripravo ocene tveganja;

- obveščanje mladih o tem, kje lahko ob odsotnosti mentorja dobijo pomoč/nasvete in kaj naj naredijo, če so v negotovosti;

- zagotavljanje, da poznajo postopke v nujnih primerih;

- objavljanje vseh pisnih dokumentov o varnih delovnih postopkih in osebni varovalni opremi/obleki, povezanih z delovnimi dolžnostmi;

- privzgajanje vrednot, pojasnjevanje pomena varnosti in zdravja pri delu, spodbujanje pravilnega odnosa, ozaveščanje in dajanje dobrega zgleda;

- $\quad$ spodbujanje, podpiranje, pospeševanje in usmerjanje;

- $\quad$ nadzorovanje, organiziranje in po potrebi kaznovanje.

Nekateri delodajalci mladim dodelijo mentorje. Mentorstvo vključuje (povzeto po nasvetih Sveta za učenje spretnosti in Kraljeve družbe za preprečevanje nezgod, ROSPA, 2006):

- poučevanje mladih o pravilnem načinu opravljanja dela, s čimer bodo pridobili temelje za svojo prihodnjo poklicno pot; 
- $\quad$ spodbujanje mladih, da sodelujejo, postavljajo vprašanja o tveganjih in varnostnih ukrepih na delovnem mestu;

- $\quad$ razpravo in poročanje o vseh nevarnostih, ki jih vidijo;

- $\quad$ željo mladih, da bi izpolnili pričakovanja, je treba koristno usmeriti;

- $\quad$ zagotovitev, da je prav, da rečejo »ne«, če ne vedo zagotovo, kaj naj storijo;

- $\quad$ poudarjanje nujnosti nošenja ustrezne varovalne opreme in uporabe pravilnih varnostnih ukrepov.

\section{SKLEP}

Delodajalec se mora zavedati ranljivosti mladih na delovnem mestu kot posledice njihove nezrelosti, pomanjkanja izkušenj in nerazumevanja vprašanj, povezanih z zagotavljanjem varnosti in zdravja pri delu. Mlade je treba zaposlovati na primernih in varnih delovnih mestih, ki ustrezajo njihovim psihofizičnim sposobnostim in njihovemu znanju ter jim zagotoviti ustrezno usposabljanje, nadzor in zaščito.

Mladim je pred začetkom dela treba zagotoviti učinkovito usposabljanje s področja varnosti in zdravja pri delu, pri čemer jih je treba še posebej opozoriti na posebne nevarnosti, ki izhajajo iz narave dela (delo z ročnim orodjem, čistili in podobno), splošne nevarnosti na delovnem mestu, na koga se obrniti v nujnih primerih, če potrebujejo prvo pomoč ali če se poškodujejo, kako naj se zaščitijo na delovnem mestu, na koga so se dolžni obrniti, če menijo, da je ogroženo njihovo življenje in zdravje, da imajo dolžnost, da se varujejo pri opravljanju dela.

Zakon o varnosti in zdravju pri delu določa (2011) pomembno temeljno načelo, po katerem morajo biti vsi izobraževalni programi na univerzah in šolah vseh vrst in stopenj oblikovani tako, da sta vzgoja in izobraževanje v zvezi z varnostjo in zdravjem pri delu sestavni del programov izobraževanja. Usposabljanje za varno in zdravo delo pa je sestavni del uvajanja v delo.

Zakonske določbe se v praksi uresničujejo z različnimi inovativnimi programi, projekti, publikacijami in aktivnostmi, ki jih ministrstvo za delo, družino, socialne zadeve in enake možnosti v sodelovanju z ministrstvom za izobraževanje, znanost in šport, Zavodom RS za šolstvo ter Nacionalnim inštitutom za javno zdravje izvaja v okviru programa uvajanja varnosti in zdravja pri delu v vzgojo in izobraževanje.

Nacionalni program uvajanja varnosti in zdravja pri delu v vzgojo in izobraževanje (Portal za varnost in zdravje pri delu, 2016) ima namen spodbujanja prizadevanj za varen in zdrav začetek poklicne poti mladih. MDDSZ je objavilo spletišče Varen začetek, na katerem so na voljo informacije za učence, dijake in študente, mlade delavce, delodajalce in starše. Namen programa je seznanjanje otrok, učencev, dijakov in študentov z osnovnimi pravili varnega dela. Program seveda nima namena postaviti varnosti in zdravja pri delu v ospredje kurikula, saj je slednji dovolj odprt, da dovoljuje učiteljevo kreativnost, zato ga po mnenju ministrstva ni treba niti spreminjati niti dopolnjevati z vsebinami varnosti in zdravja pri delu. Ocenjuje se, da so učitelji pri svojem delu 
kreativni in znajo v okviru svojih predmetov učencem predstaviti tudi praktična pravila varnega dela.

Naloga programa je predvsem v tem, da vzgojiteljem in učiteljem ter mentorjem pri praktičnem usposabljanju oziroma usposabljanju za delo ponudi različna orodja in pripomočke, s pomočjo katerih bodo lahko mladim na zanimiv način približali varnost in zdravje pri delu.

V zvezi z varnostjo mladih delavcev Evropska agencija za varnost in zdravje pri delu že vrsto let izvaja raznovrstne inovativne programe. Na uradni strani EU-OSHA je spletni portal Varen začetek, ki je namenjen mladim ter njihovemu varnemu in zdravemu začetku poklicne poti ter seznanjanju z različnimi tveganji na delovnih mestih.

Na podlagi teh aktivnosti in kampanj si je treba prizadevati za tesnejše sodelovanje vseh subjektov v vzgojno-izobraževalnem ter delovnem procesu, ki so odgovorni za varnost in zdravje pri delu s skupnim ciljem, da se zagotovi čim višja raven varnosti in zdravja pri delu mladih delavcev.

\section{LITERATURA}

Direktiva Sveta 94/33/ES o varstvu mladih ljudi pri delu. (1994). Pridobljeno s http://www.mddsz. gov.si/si/delovna_podrocja/delovna_razmerja_in_pravice_iz_dela/varnost_in_zdravje_pri_delu/ mednarodni_predpisi_s_podrocja_varnosti_in_zdravja_pri_delu/.

Evropska agencija za varnost in zdravje pri delu, EU-OSHA: bilten Facts št. 64, Varstvo mladih na delovnem mestu. (2006). Pridobljeno s http://www.osha.mddsz.gov.si/resources/files/pdf/Factsheets_64_Varstvo_mladih_na_delovnem_mestu.pdf.

Evropska agencija za varnost in zdravje pri delu, EU-OSHA: bilten Facts št. 70, Mladi delavci-dejstva in številke: izpostavljenost tveganjem in vplivi na zdravje. (2007). Pridobljeno s http://www.osha. mddsz.gov.si/resources/files/pdf/Factsheet_70_-_Mladi_delavci_2013_dejstva_in_stevilke._Izpostavljenost_tveganjem_in_vplivi_na_zdravje.pdf.

Okvirna direktiva Sveta 89/391/EGS o uvajanju ukrepov za spodbujanje izboljšav varnosti in zdravja delavcev pri delu (1989). Pridobljeno s http://www.mddsz.gov.si/si/delovna_podrocja/delovna_razmerja_in_pravice_iz_dela/varnost_in_zdravje_pri_delu/ mednarodni_predpisi_s_podrocja_varnosti_in_zdravja_pri_delu/.

Portal za varnost in zdravje pri delu, Uvajanje varnosti in zdravja pri delu $v$ vzgojo in izobraževanje. (2016). Pridobljeno s http://www.osha.mddsz.gov.si/aktivnosti/projekti/ vkljucevanje-varnosti-in-zdravja-pri-delu-v-izobrazevanje.

Portal za varnost in zdravje pri delu. (2016). Pridobljeno s http://www.osha.mddsz.gov.si/ varnost-in-zdravje-pri-delu/informacije-za-prednostne-skupine/mladi.

Pravilnik o varovanju zdravja pri delu otrok, mladostnikov in mladih oseb. (2015). Pridobljeno s https:// www.uradni-list.si/1/content?id=122956.

Svet za učenje spretnosti in Kraljeve družbe za preprečevanje nezgod, ROSPA. Evropska agencija za varnost in zdravje pri delu, EU-OSHA: bilten Facts št. 62, Varnost mladih delavcev - nasveti za nadzornike. (2006). Pridobljeno s http://www.osha.mddsz.gov.si/resources/files/pdf/Factsheets_62_-_ Sicherheit_junger_Arbeitnehmer_2013_Hinweise_fur_Aufsichtfuhrende.pdf.

Zakon o delovnih razmerjih. (2013). Pridobljeno s https://www.uradni-list.si/1/content?id=112301.

Zakon o varnosti in zdravju pri delu (2011). Pridobljeno s http://www.uradni-list.si/1/objava. jsp?urlid=201143\&stevilka=2039. 